\title{
Validation of a semi-quantitative food frequency questionnaire for estimating dietary omega-3 fatty acids intake among urban Indonesian pregnant women
}

\author{
Dudung Angkasa ${ }^{1,2}$, Rina Agustina ${ }^{1,3^{*}}$, Helda Khusun ${ }^{4}$ \& Erfi Prafiantini ${ }^{1,3}$ \\ ${ }^{1}$ Department of Nutrition, Faculty of Medicine, Universitas Indonesia - Dr. Cipto \\ Mangunkusumo General Hospital, Jakarta, Indonesia; ${ }^{2}$ Department of Nutritional \\ Science, Faculty of Health Sciences, Universitas Esa Unggul, Jakarta, Indonesia; \\ ${ }^{3}$ Human Nutrition Research Center, Indonesian Medical Education and Research \\ Institute, Faculty of Medicine, Universitas Indonesia, Jakarta, Indonesia; ${ }^{4}$ Southeast \\ Asian Ministers of Education Organization Regional Center for Food and Nutrition \\ (SEAMEO RECFON), Jakarta, Indonesia
}

\begin{abstract}
Introduction: Studies on the development and validation of semi-quantitative food frequency questionnaires (SQ-FFQ) for assessing omega-3 ( $\Omega$-3) long-chain polyunsaturated fatty acids (LC-PUFAs) intake by pregnant women are few. This study aimed to determine the validity of a newly developed SQ-FFQ for assessing the LC-PUFA intake among Indonesian urban pregnant women. Methods: A crosssectional study was carried out in 2015 on 100 Indonesian pregnant women who were in their late $3^{\text {rd }}$ trimester, living in the urban setting of Jakarta. As a test tool, the SQ-FFQ was administered before the trained nutritionists executed the reference tool of non-consecutive two-day 24-hour dietary recalls (2DRs). The nutrients of interest were a total of $\Omega-3$, eicosapentanoic acid (EPA), docosahexaenoic acid (DHA), alpha-linolenic acid (ALA), total $\Omega-6$, linoleic acid (LA), arachidonic acid (AA), and LC-PUFAs. Statistical correlation, cross-classification and the Bland-Altman plot analysis were done to determine the agreement between tools. Results: Energy-adjusted correlation coefficients between SQ-FFQ and 2DRs were 0.385, $0.349,0.352,0.380,0.338,0.408,0.409,0.331,0.341$ and 0.341 for fat, total $\Omega-3$, ALA, EPA, DHA, total $\Omega-6$, LA, AA and LC-PUFAs, respectively and were statistically significant $(p<0.05)$. Misclassification of these nutrients from SQ-FFQ and 2DRs was $<6 \%$. The Bland-Altman plots showed most of the points fell within the $95 \%$ limits of acceptable agreement for DHA, EPA, and LA. Conclusion: The newly developed SQ-FFQ of this study is a valid instrument for assessing of $\Omega-3$ LC-PUFAs intake among Indonesian pregnant women living in urban area. Its further validation with relevant biomarkers is recommended.
\end{abstract}

Keywords: Semi-quantitative food frequency questionnaire, validation, fatty acids, pregnancy, omega-3, omega-6

\footnotetext{
*Corresponding author: Rina Agustina, MD, Ph.D

Department of Nutrition, Faculty of Medicine, Universitas Indonesia

Dr.Cipto Mangunkusumo General Hospital, Jakarta, Indonesia

Email: dr.rinaagustina@gmail.com; r.agustina@ui.ac.id

doi: https://doi.org/10.31246/mjn-2019-0027
} 


\section{INTRODUCTION}

Omega-3 $(\Omega-3) \quad$ long chain polyunsaturated fatty acids (LC-PUFAs) such as docosahexaenoic acid (DHA), eicosapentaenoic acid (EPA) and alphalinolenic acid (ALA), are important modifiable dietary factors associated with birth outcome (Koletzko et al., 2014; Muthayya et al., 2009). However, the dietary reference intakes (RDI) for these $\Omega$-3 LC-PUFAs have not been reported in either developed (Colón-Ramos et al., 2015) or developing countries (Koletzko et al., 2014). Systematic reviews on the association between $\Omega-3$ LC-PUFAs intake and birth outcome in developing countries are limited and there have been reports only from Indonesia, India and Bangladesh (Angkasa et al., 2017; Koletzko et al., 2014).

The Indonesian Central Bureau of Statistics has reported that the consumption of fish by the Indonesian people was low (Central Bureau of Statistic, 2014). Based on household survey statistics of the Food and Agriculture Organization (FAO), fish consumption of the Indonesian people when compared to that of eight countries in Southeast Asia region was lower than those in Lao, Myanmar, Thailand, Philippines, and Cambodia and lower than the average global consumption of fish (FAO, 2016). As fish and fish products are the main source of $\Omega$-3 LC-PUFAs (Freeman et al., 2006), most pregnant women in Indonesia were unlikely to have adequate intakes of DHA and EPA. This situation exists especially in women from the low-medium socioeconomic background, living in urban areas with limited access to fish that are rich in essential fatty acids. Such women have a poor knowledge of the benefits and sources of essential fatty acids and are unable to afford the relatively expensive fish that are high in $\Omega-3 \mathrm{LC}$ PUFAs. Therefore, the monitoring of regular maternal diet is required to assess the adequacy of $\Omega-3$ LC-PUFAs intake, especially DHA and EPA during pregnancy. Tools for assessing dietary $\Omega$-3 LC-PUFAs have been developed and validated for Indonesian children (Ansari et al., 2016). Such validated tools for pregnant women are few, and are mainly available for women who are living in developed countries with a high consumption of fish such as Japan (Kobayashi et al., 2017).

The semi-quantitative food frequency questionnaire (SQ-FFQ) is a method to assess usual intake and is widely used to study the relationship between maternal diet and birth outcome in developing and developed countries (Muthayya et al., 2009; Willett, 2012; Zhang et al., 2015). This tool is relatively convenient, inexpensive, and requires less time for data collection than other dietary assessment methods. SQ-FFQ is able to show the long-term dietary intake patterns. It is also a valid and reliable tool for detecting the changes in dietary intake during each trimester of pregnancy. Validation studies of SQFFQ have shown that nutrient estimates using this method agree closely with intake estimates using the 24-hour dietary recall method, particularly among pregnant women with low literacy levels or motivation (Brunst et al., 2016; Gibson, 2005).

In this study, we developed and validated a SQ-FFQ for assessing dietary $\Omega$-3 LC-PUFAs intake in Indonesian pregnant women living in the urban areas of Jakarta.

\section{MATERIALS AND METHODS}

\section{Study design}

This cross-sectional study was carried out between February and May 2015. It was part of the East Jakarta Cohort Study on "The Role of Nutrition, Maternal Factors, and Health Service 
in Microbiota Composition and Birth Weight in Jakarta" that was initiated by Department of Nutrition, Faculty of Medicine, Universitas Indonesia (Angkasa et al., 2017).

\section{Participants and recruitment}

A total of 100 women were randomly selected from 315 pregnant women recruited at the third trimester. They fulfilled the inclusion criteria in being apparently healthy, pregnant women aged 19-40 years, at the gestational age of $>32$ weeks, who were registered for antenatal care in ten sub-district public health centres (PHCs) and one referral hospital in East Jakarta. The under- and over- reporting of energy intakes of the women were excluded from this study. Under-reporting was determined by Goldberg method (Goldberg et al., 1991), in which basal metabolism rate (BMR) of each pregnant women was calculated by Schofield equation for women of their age (Schofield, 1984). The cut-off value for over-reporting of energy was set as $>4700$ kcal (Ambrosini et al., 2011). Written informed consent was obtained from all respondents. The sample size of 100 was determined following a minimum sample size required for Bland-Altman analysis (Bland \& Altman, 1999) and also in accordance to another validation study of pregnant women in developing countries (Muthayya et al., 2009).

\section{Data collection}

Data on age, schooling, socioeconomic status and obstetric history were collected using a structured questionnaire based on the categories determined by the National Basic Health Survey (National Institute of Health Research and Development, 2013). The anthropometric status of the pregnant mothers was measured using calibrated tools namely the SECA ${ }^{2}$ tape (SECA 201, UK) for middle upper-arm circumference
(MUAC) measurement, the Shorr board ${ }^{\circledR}$ height measurement for mothers' height and the Tanita ${ }^{\circledR}$ calibrated weighing scale for mothers' weight. All measurements were conducted twice and the means of the measurements were inputted for further statistical analysis.

Before performing the validity test, the initial SQ-FFQ was developed by collecting potential food lists that contained high LC-PUFA from the Indonesian food composition database, and some previous studies among pregnant and urban women (Madanijah et al., 2016). The draft was pre-tested among ten pregnant women in the same study area, but who were not included as participants. Using this prototype SQFFQ, participants were asked to report the foods they had consumed during the previous month. In addition, a single 24-hour food recall was administered to another twenty pregnant women in the same area for the completion of the food lists. Information on the common $\Omega$-3 food sources and accessed foodmarket were emphasized during pretesting phase. Commonly accessed food-markets were visited and some relevant foods were weighted for the food portion size. The prototype SQ-FFQ was subsequently revised based on the results of pretesting and market survey to its final form. Five trained nutritionists used the final questionnaire, which sought information of food items that were appropriate to describe the sources of fatty acids and adequate to assess the fatty acids content in individual, mixed or processed foods. The description of the portion sizes format of the SQ-FFQ were categorized as small, medium and large. The consumption frequency consisted of seven possible categories ranging from never or once a month to $>1$ a day. The final questionnaire included 53 items, and was grouped into seven food categories, as follows: staple food, animal protein rich-food, plant protein 
rich-food, dairy product, certain fruits, ready-to-eat product (e.g. ice cream), and supplements.

The two-day, non-consecutive, 24-hour diet recalls (2DRs) method was chosen as a reference, as was also used by another study (Loy et al., 2011). This 2DRs were administered twice representing one day in weekend and one day in weekday. Both SQFFQ and 2DRs were administered by trained nutritionists (Gibson, 2005). Conversion of household measures into grams of food consumed was carried out with the aid of an Indonesian food photograph from national total diet study (National Institute of Health Research and Development, 2014), which contained data on recipes and household measures. In cases where the food was not available in this manual, the research team conducted a market survey, bought and weighed the same portions of the foods. Conversion of processed foods from wet to dry or the reverse was calculated following the national guidelines on raw-cook food conversion (National Institute of Health Research and Development, 2014).

The nutrients of interest in the present study were the total $\Omega$-3 LC-PUFA, EPA, DHA, ALA, total $\Omega-6$, LA and AA. The estimation of nutrient composition of the FFQ was analysed using the Nutrisurvey software version 2007 (Erhardt, 2014). Until this study was done, an Indonesian Food Composition Table (FCT) for $\Omega-3$ FAs content was not available. Therefore, the current study used FCTs from other countries. Calculation of Indonesian $\Omega-3$ FAs food was estimated by using values from different but similar food items from several ASEAN countries (Berger et al., 2013). In order of priority, we used FCTs from the Association of Southeast Asian Nations (ASEAN) countries (Puwastien et al., 2000) such as Vietnam and Malaysia and the United States Department of
Agriculture (USDA) (Schakel, Buzzard \& Gebhardt, 1997).

\section{Data analyses}

The general characteristics of the participants are presented as frequency and percentage for categorical variables. Continuous variables with normal distribution, were tested by KolmogorovSmirnov, and expressed as mean and standard deviation (SD), and those with violated distribution are presented as median and interquartile range. For validation testing, Pearson's correlation and paired t-test were used for normally distributed data. The Spearman and Wilcoxon signed rank test was used for non-normally distributed data. Crossclassification was presented as correctly classified, correctly and adjacent classified, and extremely misclassified quintile. All nutrient intakes were log transformed $\left(x^{+1}\right)$. Energy-adjusted nutrient intakes were calculated as the residuals from the regression of nutrient intake as the dependent variable while energy was the independent variables (Willett, 2012). The Bland-Altman scatter plot was also produced from the mean (bias) of SQ-FFQ and 2DRs against difference of SQ-FFQ and 2DRs. The Limits of Agreement (LoA) was calculated by mean+1.96 SD for upper LoA and mean-1.96 SD for lower LoA (Bland \& Altman, 1999). Antilog of the mean bias and LoA were multiplied by 100 , in which value close to one or $100 \%$ represented perfect agreement. The regression coefficient was also produced to estimate under or overestimate of average intake between two methods. All significant values were set at $p<0.05$. All statistical tests were calculated using the SPSS version 21.0 for Windows software. The Bland-Altman scatter plot or graph was drawn by Prism 6 for Windows version 6.05 software. 


\section{Ethical approval}

The study was approved by the ethical committee of the Faculty of Medicine of Universitas Indonesia and the Dr. Cipto Mangunkusumo General Hospital, Jakarta, Indonesia under the serial number 859/UN2.F1/ETIK/2014. The local authority of East Jakarta District, District Health office of East Jakarta, and sub-districts Public Health Center also gave their approval for the study.

\section{RESULTS}

Table 1 presents the baseline characteristics of the pregnant women. Their median age was 28 years. More than half of the mothers had at least 12 years of formal education and most of them were housewives with a median household income of 2.6 million rupiahs ( 196 US Dollars) per month. More than half of pregnant women were exposed to smoking in their daily lives. More than a third of women (39\%) were nulliparous. Only small number of pregnant mothers had a history of premature births $(n=7)$, abortions $(\mathrm{n}=8)$ and low birth weight infants $(n=11)$. At recruitment, the mean gestational age of the pregnant mothers was 35.5 weeks. Mean MUAC and body height; and median body weight of pregnant women were $27.2 \mathrm{~cm}, 153.4$ $\mathrm{cm}$, and $61.6 \mathrm{~kg}$, respectively.

Table 2 shows the mean daily intakes of $\Omega$-3 fatty acids as assessed by the SQFFQ and 2DRs. Except for energy, fat, total $\Omega-6$ and LA, the mean intake of the measured nutrients as estimated by

Table 1. Sociodemographic characteristics and nutritional status of the 100 pregnant women of this study

\begin{tabular}{|c|c|c|}
\hline Variables & $n(\%)$ & Mean $\pm S D$ \\
\hline \multicolumn{3}{|l|}{ Sociodemographic } \\
\hline Mother's age, years & & $28(25-31.8)^{\dagger}$ \\
\hline \multicolumn{3}{|l|}{ Education, years } \\
\hline$<12$ & $25(20)$ & \\
\hline$\geq 12$ & $75(80)$ & \\
\hline \multicolumn{3}{|l|}{ Working status } \\
\hline Working & $27(27)$ & \\
\hline Housewife & $73(73)$ & \\
\hline Household income in million & & $2.6(2.0-3.5)^{\dagger}$ \\
\hline Daily smoking exposure, yes & $53(53)$ & \\
\hline \multicolumn{3}{|l|}{ Obstetric profiles } \\
\hline \multicolumn{3}{|l|}{ History of } \\
\hline Nulliparous & 39 (39) & \\
\hline Premature birth $(n=58)$ & $7(12.1)$ & \\
\hline Abortion $(\mathrm{n}=61)$ & $8(13.1)$ & \\
\hline Low birth weight $(n=58)$ & 11 (19) & \\
\hline Gestational age, weeks & & $35.5(34.0-36.9)^{\dagger}$ \\
\hline \multicolumn{3}{|l|}{ Maternal antrophometric } \\
\hline MUAC, $\mathrm{cm}$ & & $27.2 \pm 2.9$ \\
\hline Height, $\mathrm{cm}$ & & $153.4 \pm 5.1$ \\
\hline Weight, kg & & $61.6(57.1-69.5)^{\dagger}$ \\
\hline
\end{tabular}

${ }^{\dagger}$ Median (quartile $25^{\text {th }}-75^{\text {th }}$ )

${ }^{\ddagger}$ Rupiah/month, 1 US Dollars = 13.000 Rupiahs 
Table 2. Validation study: comparison, Spearman correlation (SC) and cross classification of mean daily intakes of fat and fatty acids between SQ-FFQ and the 2DRs

\begin{tabular}{|c|c|c|c|c|c|c|c|c|c|c|}
\hline \multirow{2}{*}{$\begin{array}{l}\text { Energy/ } \\
\text { Nutrients }\end{array}$} & \multicolumn{2}{|c|}{$S Q-F F Q$} & \multicolumn{2}{|c|}{$2 D R s$} & \multirow{2}{*}{$p$-value $e^{\dagger a}$} & \multicolumn{2}{|c|}{$S C(r)$} & \multicolumn{3}{|c|}{ Cross C } \\
\hline & Mean & $S D$ & Mean & $S D$ & & Crude $^{\dagger}$ & Adjusted & $C C$ & $C C / A C$ & IC \\
\hline Energy (kcal) & 2025 & 635 & 2186 & 527 & $0.001^{*}$ & $0.386^{*}$ & - & 25 & 87 & 3 \\
\hline Fat $(g)$ & 64.2 & 31.5 & 75.5 & 26.3 & $0.000^{*}$ & $0.348^{*}$ & $0.385 * \S$ & 36 & 88 & 3 \\
\hline Total $\Omega-3$ (g) & 11.30 & 7.83 & 6.82 & 4.72 & $0.000 * \pi$ & $0.309 * \$$ & $0.349 *$ & 22 & 88 & 5 \\
\hline ALA $(g)$ & 11.00 & 7.83 & 6.57 & 4.70 & $0.000 * \pi$ & $0.310 * \S$ & $0.352^{*}$ & 26 & 88 & 4 \\
\hline EPA (g) & 0.14 & 0.16 & 0.13 & 0.21 & $0.014^{*}$ & $0.308^{*}$ & $0.380^{*}$ & 26 & 88 & 5 \\
\hline DHA (g) & 0.17 & 0.14 & 0.12 & 0.15 & $0.000^{*}$ & $0.201^{*}$ & $0.338^{*}$ & 26 & 80 & 4 \\
\hline Total $\Omega-6$ (g) & 1.35 & 1.40 & 4.47 & 11.30 & 0.062 & 0.118 & $0.408^{*}$ & 24 & 80 & 6 \\
\hline LA (g) & 1.17 & 1.37 & 4.38 & 11.40 & 0.091 & 0.118 & $0.409^{*}$ & 20 & 79 & 4 \\
\hline AA (g) & 0.17 & 0.12 & 0.10 & 0.08 & $0.000 *$ & $0.211^{*}$ & $0.331^{*}$ & 29 & 84 & 6 \\
\hline LC-PUFA (g) & 12.60 & 8.62 & 11.30 & 12.40 & $0.002 * \pi$ & $0.213^{* \S}$ & $0.341^{*}$ & 22 & 85 & 3 \\
\hline Average & & & & & & 0.25 & 0.37 & 25.6 & 84.7 & 4.30 \\
\hline
\end{tabular}

$\mathrm{N}=100$

thased on log-transformed values

‡energy-adjusted, residual of linear regression, energy as dependent while nutrients as independent (17)

\$Pearson's correlation $\mathrm{r}$

aWilcox son signed rank test

"paired t-test

*significantly correlated, $p<0.05$

$\mathrm{CC}=$ correctly classified; $\mathrm{AC}=$ adjacent classified; $\mathrm{IC}=$ incorrectly classified. $\mathrm{ALA}=\alpha$-linolenic acid; $\mathrm{EPA}=$ eicosapentaenoic acid; $\mathrm{DHA}=$ docosahexaenoic acid; $\mathrm{LA}=$ linoleic acid; $\mathrm{AA}=$ arachidonic acid; LC-PUFA= long chain polyunsaturated fatty acids; SQ-FFQ = semi-quantitative food frequency questionnaires; 2DRs = two-day 24-hour dietary recalls

Table 3. Validation study: mean differences between SQ-FFQ and the 2DRs, the limits of agreement and the slope with 95\% confidence intervals for a linear regression of the difference against the means of the two methods

\begin{tabular}{|c|c|c|c|c|c|c|c|c|}
\hline $\begin{array}{l}\text { Fatty } \\
\text { Acids }^{\dagger}\end{array}$ & Mean & $S D$ & $\begin{array}{c}\text { LoA } \\
\text { lower, upper }\end{array}$ & Slope & $95 \% C I$ & Mean ${ }^{\S}$ & $S D$ & $L o A$ \\
\hline Fat & 09 & 0.21 & $-0.51,0.32$ & & $0.25,0.79$ & 0.81 & 1.63 & $0.31,2.10$ \\
\hline Total $\Omega-3$ & 0.20 & .29 & $-0.38,0$ & -0.07 & $-0.36,0.22$ & 1.58 & 1.96 & .93 \\
\hline ALA & 0.21 & 0 & -0.39 & & $-0.41,0$ & & 2.00 & $.41,6.23$ \\
\hline EPA & 0.01 & 0.07 & $-0.13,0$ & & $-0.65,0.12$ & & 1. & \\
\hline DHA & & 0.06 & $-0.10,0.14$ & -0.0 & $-0.41,0.22$ & & 1.1 & $0.80,1.37$ \\
\hline Total $\Omega-6$ & -0.05 & 0.42 & $-0.87,0.78$ & -1.32 & $-1.54,-1.1$ & 0.89 & 2.63 & $0.13,5.96$ \\
\hline LA & -0.06 & 0.43 & $-0.90,0.78$ & -1.34 & $-1.56,-1.12$ & 0.87 & 2.69 & $0.12,6.07$ \\
\hline $\mathrm{AA}$ & & & $-0.06,0.12$ & & $0.16,0.79$ & 1.07 & 1.12 & $0.86,1.33$ \\
\hline LC-PUFA & 0.12 & 0.37 & $-0.61,0.84$ & -0.50 & $-0.81,-0.19$ & 1.31 & 2.33 & $0.25,6.87$ \\
\hline
\end{tabular}

${ }^{\dagger}$ All variables were transformed by $\log (\mathrm{x}+1)$

*Linear regression

santilog $\left(10^{\mathrm{y}}\right)$, agreement if the value close to 1

$\mathrm{ALA}=\alpha$-linolenic acid; $\mathrm{EPA}=$ eicosapentaenoic acid; DHA= docosahexaenoic acid; LA=linoleic acid; $\mathrm{AA}=$ arachidonic acid; LC-PUFA= long chain polyunsaturated fatty acids 


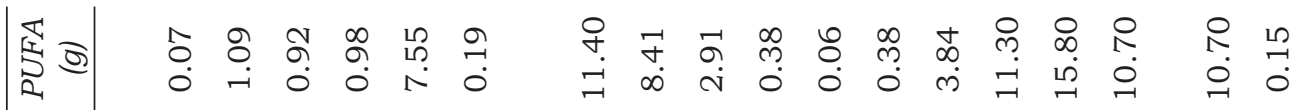

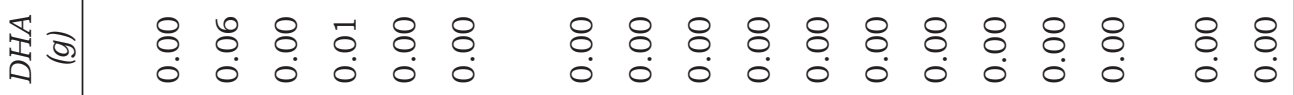
$\begin{array}{llllllllllllllllllll}\mathbb{4} & 0 & 8 & 0 & 8 & -1 & 8 & 8 & 8 & 8 & 8 & 8 & 8 & 8 & 8 & 8 & 8 & 8 & 8 & 8 \\ 0 & 0 & 0 & 0 & 0 & 0 & & 0 & 0 & 0 & 0 & 0 & 0 & 0 & 0 & 0 & 0 & 0 & 0\end{array}$ 在 莳

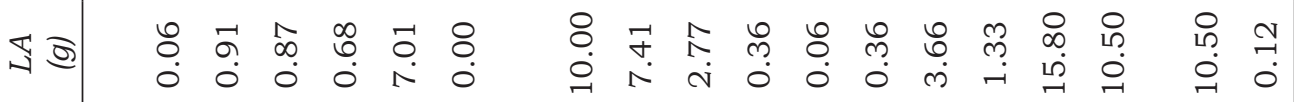

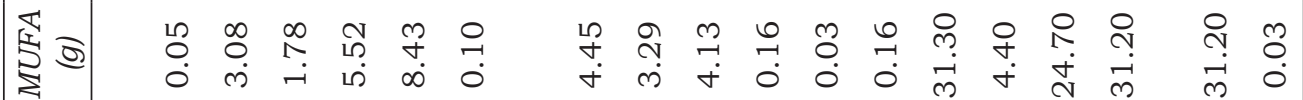

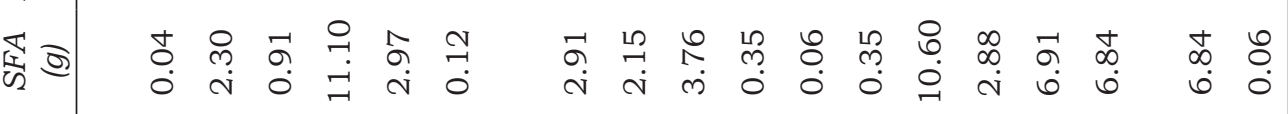

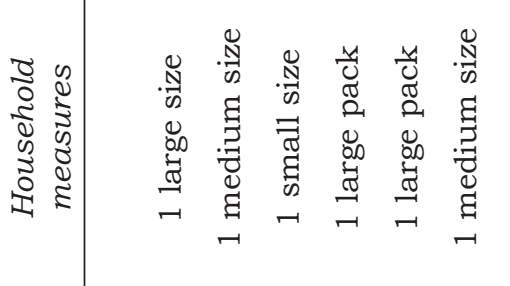

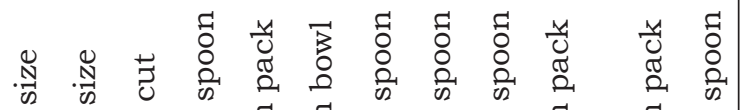

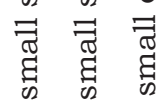
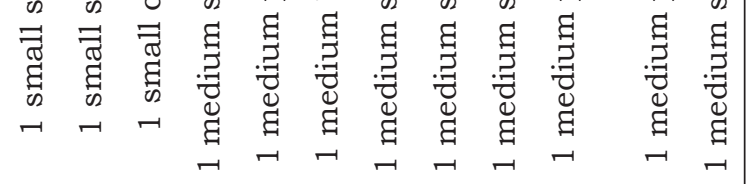

\section{ஓ}

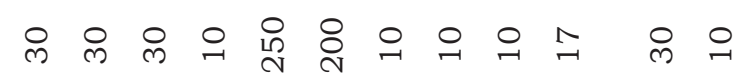




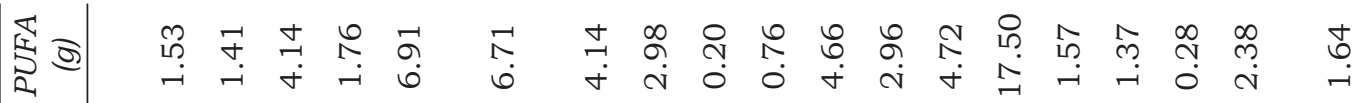
壳

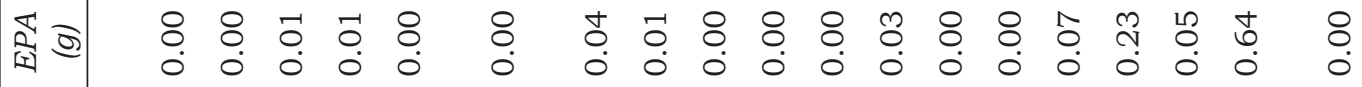

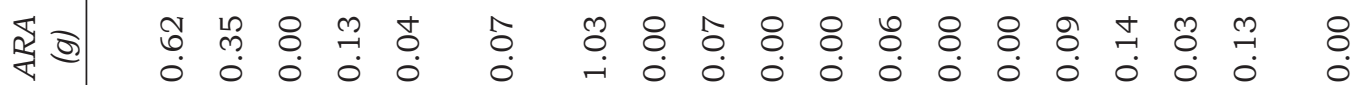

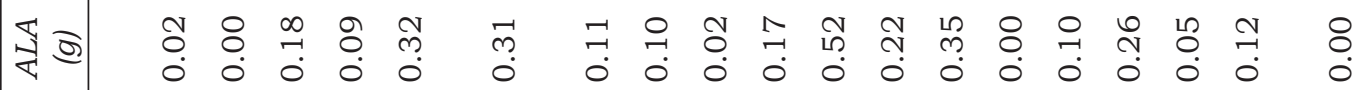

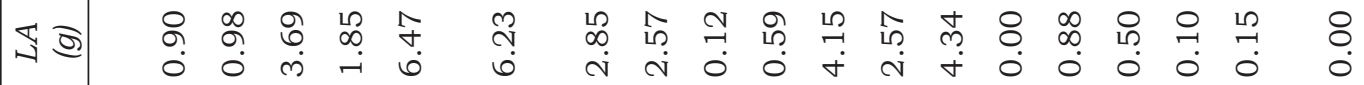

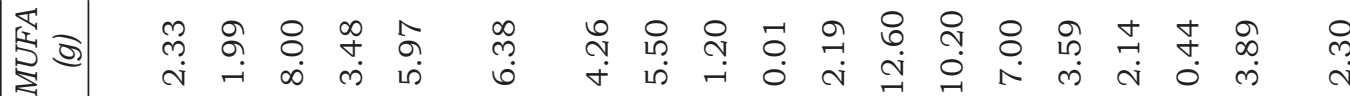

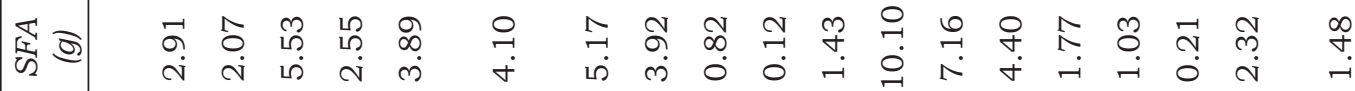

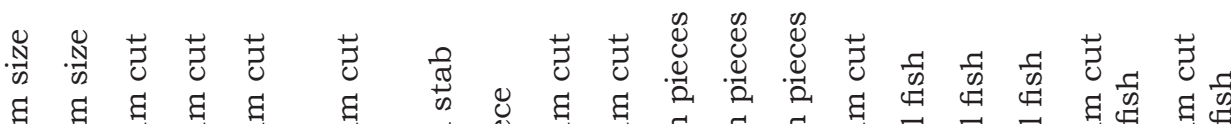

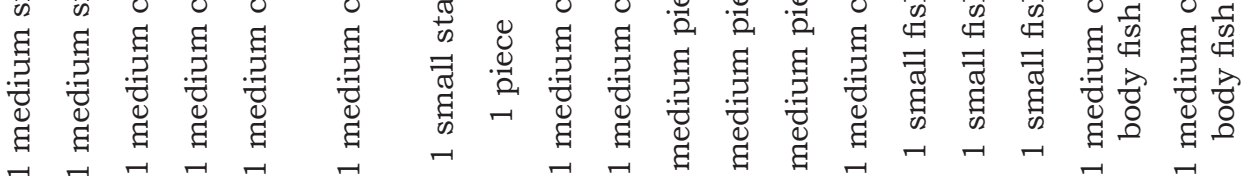

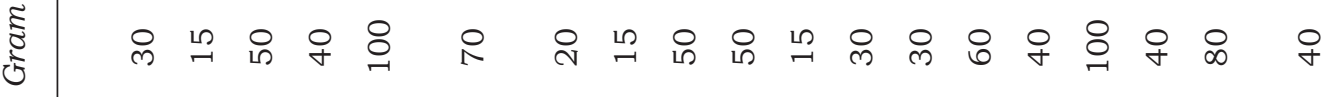

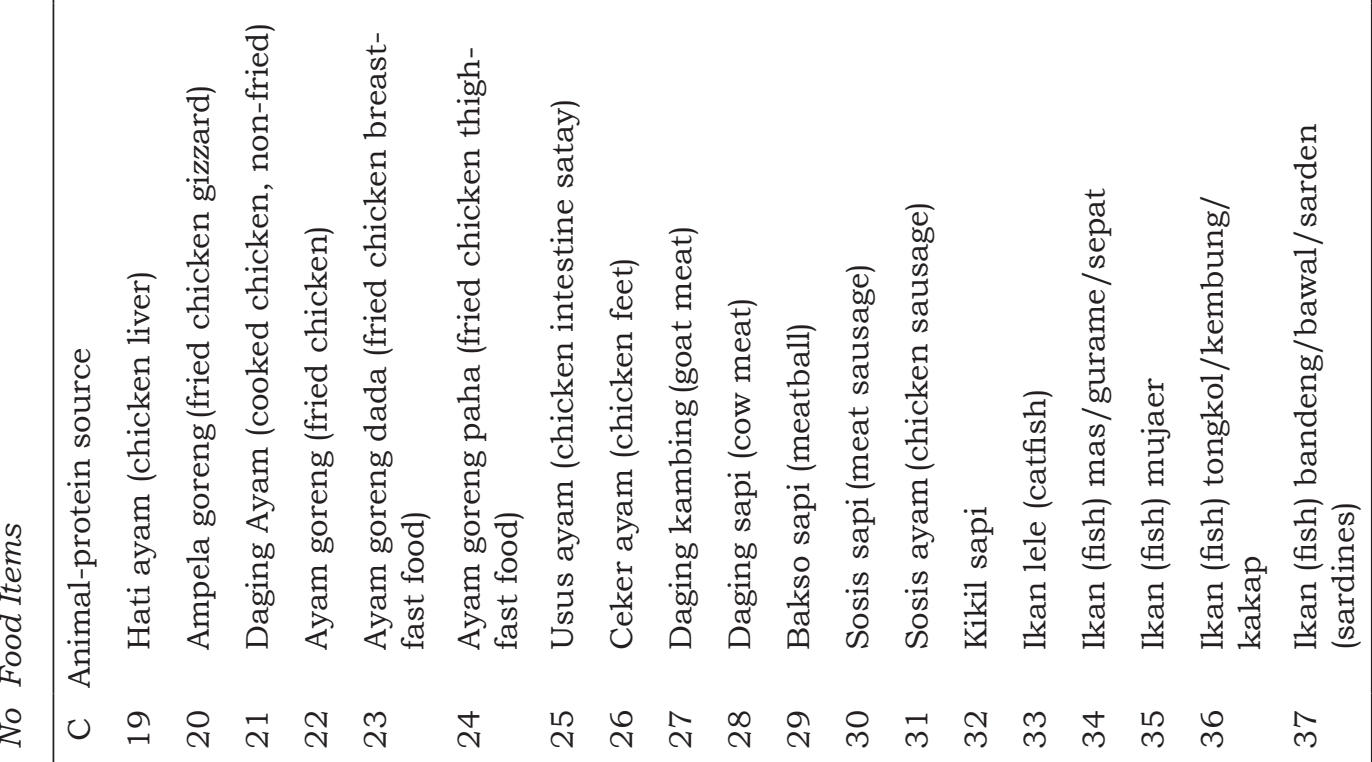




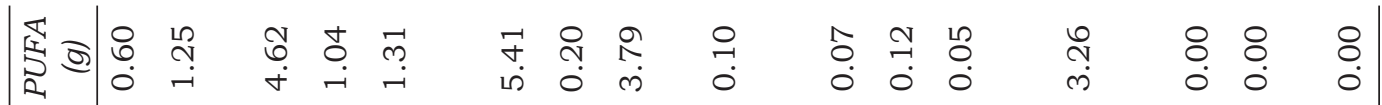
壳

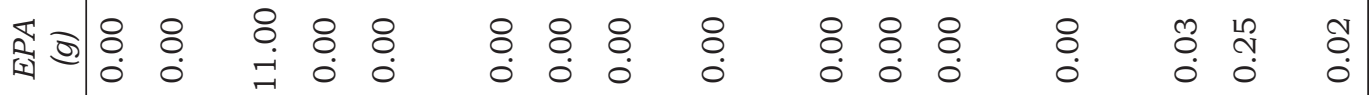
蛋 声

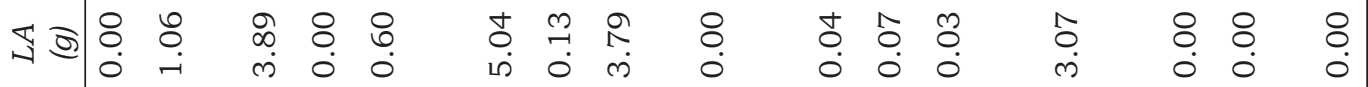
疍 秃

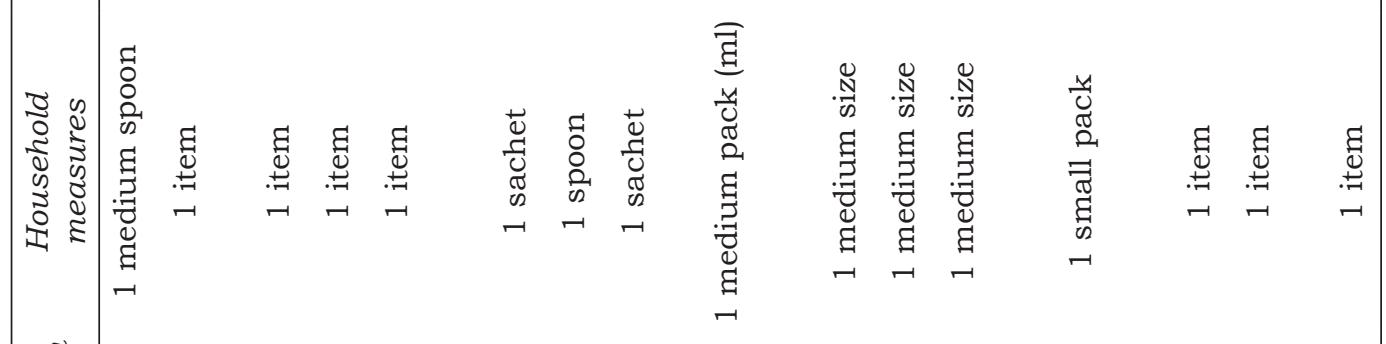

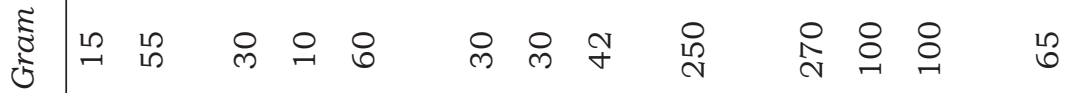

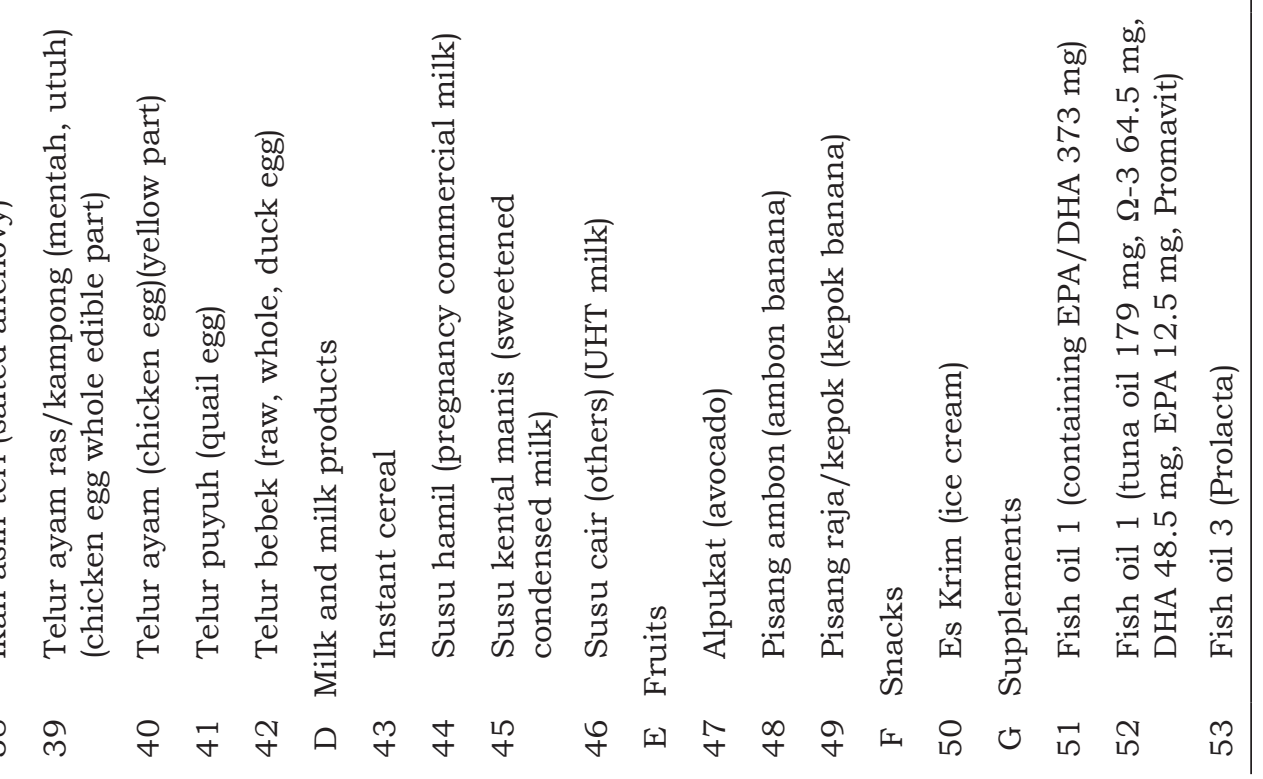


(a)

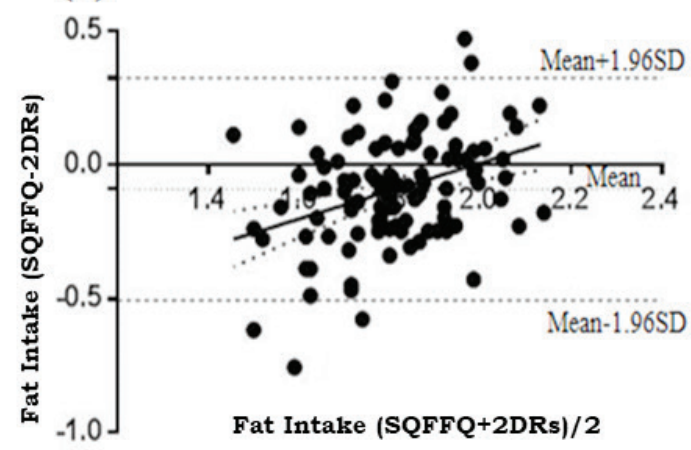

(c)

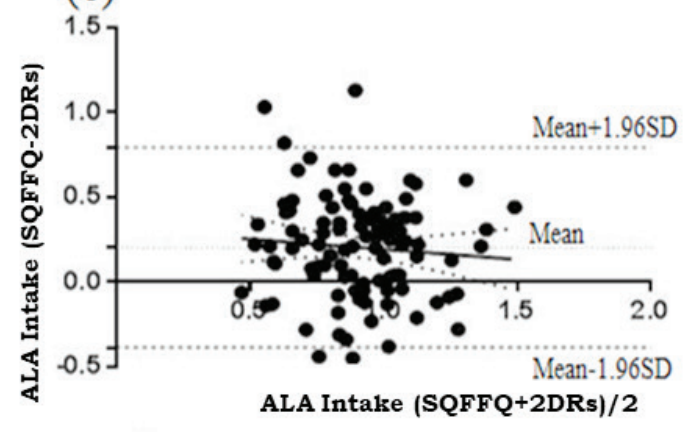

(b)

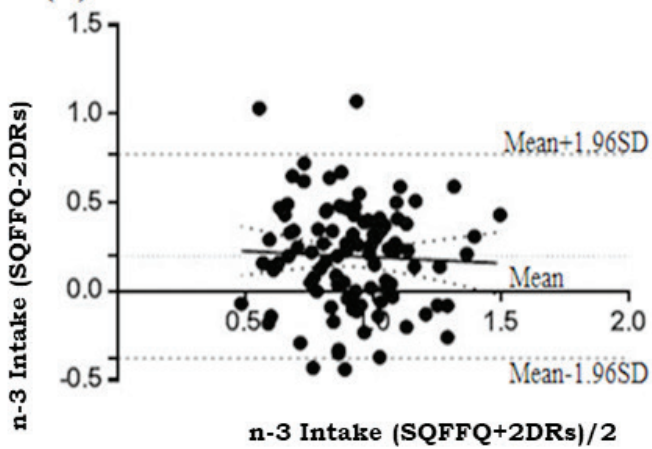

(d)

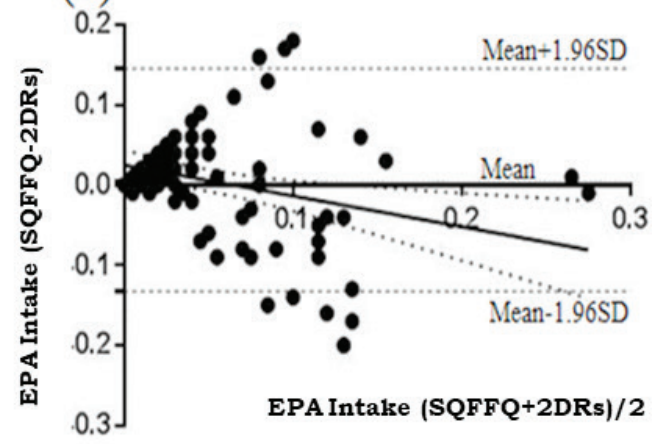

Figure 1. Bland-Altman plot showing agreement between the average of SQ-FFQ and the 2DRs in estimating the intakes of (a) fat, (b) n-3, (c) ALA, alpha linolenic acid and (d) EPA, eicosapentaenoic acid. After natural log transformation. SQ-FFQ = semi-quantitative food frequency questionnaires; 2DRs = two-day 24-hour dietary recalls

SQ-FFQ were significantly higher (4.44, 4.38, 0.01, 0.05, 0.07 and $1.31 \mathrm{~g} / \mathrm{d}$ for total $\Omega-3$, ALA, EPA, DHA, AA and LCPUFA, respectively) than the mean intake estimated by 2DRs. Table 2 also presents the unadjusted Spearman correlation coefficients between both methods ranging from 0.118 for total $\Omega-6$ and LA to 0.386 for energy intake. The Spearman correlation coefficients increased after energy adjustment for all nutrients. The most obvious changes compared with the unadjusted values occurred in the total S-6 (from 0.118 to 0.408 ) and LA (from 0.118 to 0.409$)$. Overall, the average correlation coefficient of all nutrients was $r=0.25$ and after energy adjustment, the average of correlation coefficients improved for 0.12 points ( $r=0.37)$. All the energy-adjusted coefficients for fat and fatty acids were statistically significant $(p<0.05)$ between two methods. A high proportion of the pregnant women $(>79$ $\%)$ were categorised into the same or adjacent quintiles by the SQ-FFQ vs quintiles of 2DRs for energy and all fatty acids intakes. On the average, about $4.3 \%$ of pregnant women were in extreme misclassifications. Bland Altman plots showed acceptable agreement between the SQ-FFQ and 2DRs for DHA, EPA and $\mathrm{AA}$, as indicated in Table 3 . The values of the antilog mean for DHA (1.05 or $105 \%)$, EPA (1.01 or $101 \%)$ and AA (1.07 or $107 \%$ ) were close to one (or $100 \%$ ) and the values of LoA were narrow 
(DHA 80-137\%; EPA 74-140\%; AA 86\%; $133 \%)$ which indicated good agreement between both methods.

Table 4 shows the food groups, food items, standard portion sizes and content of LC-PUFA. Plant proteinsources from legumes family contained the highest amount of LA and ALA in the new developed SQ-FFQ and were also the most frequent consumed food source for both LA and ALA intake among pregnant women. Soy and its products such as tofu and tempeh contained almost $10 \mathrm{~g}$ ALA/100g while peanut and its products contained about $0.15 \mathrm{~g}$ per gram of peanuts. The highest amount of EPA was in chicken egg $(11 \mathrm{~g} / 100 \mathrm{~g})$ and fish $(0.64$ $\mathrm{g} / 100 \mathrm{~g})$ while chicken intestine satay $(1.02 \mathrm{~g} / 100 \mathrm{~g})$ and chicken liver (0.61 g/ 100 g) contained the highest amount of ARA. Except from the supplement $(0.97$ g/ 1 capsule), a high amount of DHA intake was derived from catfish $(0.21$ $\mathrm{g} / 100 \mathrm{~g})$, mackerel tuna $(0.15 \mathrm{~g} / 100 \mathrm{~g})$ and yellow egg (0.12 g/100 g). Figure 1 shows the Bland-Altman plots for fat, total $\Omega-3$, DHA, and EPA intakes. Most of the points fell within the $95 \%$ limits of agreement (LoA) for total $\Omega-3$, DHA, EPA, and ALA intakes. Except from total fat, $\Omega-6$ and LA, the SQ-FFQ overestimated all fatty acids intake from 2DRs.

\section{DISCUSSION}

The current study presents a newly developed SQ-FFQ, with 53 food items, that we believe is valid for estimating dietary DHA, EPA and AA intake among Indonesian pregnant women in the third trimester. The Bland-Altman plots imply acceptable agreement between the SQFFQ and reference method (two-repeated 24-h recalls) for these nutrients as the mean values of the antilog for these nutrients were close to one (or $100 \%$ ) and the values of LoA were narrow. The analyses of correlation coefficient and a cross-classification also indicated a good relative validity of the SQ-FFQ in assessing intake of fat and fatty acids. Agreement based on the comparison test was found for the total $\Omega-6$ and LA.

In a validation study, several tests including Cohen's kappa coefficient (к) might be used to find agreement between methods. However, not all tests were appropriate for use in this study. We prioritised the results of the BlandAltman test for generating the conclusions of this study because this approach was appropriate for quantitative variables (Zhang et al., 2015) as shown by some other studies (Kobayashi et al., 2017; Zhang et al., 2015). In the Bland-Altman Test, the agreement of both methods was met when antilog of mean (bias) was close to one and the interval of LoA was narrow. We assumed that the antilog of mean (bias) for DHA, EPA and AA were sufficiently close to one and the SD of those nutrients were intuitively narrow. The study of Ansari et al. (2016) reported almost similar antilog means and SD of DHA between SQ-FFQ and three-day, 24-hour food recalls as in the Indonesian children's study. Therefore, the Bland Altman test could support the use of the SQ-FFQ as a valid instrument for assessing LC-PUFA $\Omega-3$ a in larger study. A comparison of both methods, indicated that there was a tendency for SQ-FFQ to overestimate the dietary recalls as reported by Ansari et al. (2016). On the contrary, other tests, such as the $t$-test and correlation coefficient were not appropriate to show agreement. The $t$-test informed us very little about the accuracy of the methods (Bland \& Altman, 1999) while the correlation test evaluated only the linear association of two sets of observations (Bland \& Altman, 1999; Zhang et al., 2015). These approaches were inadequate and could be very misleading when assessing agreement. 
The correlation coefficients of most validation studies that compared the two dietary methods ranged between 0.30 and 0.49 (Streppel et al., 2013; Zhang et al., 2015). However, in most of the studies, energy-adjustment or deattenuation increased the correlation of the methods assessed (Barbieri et al., 2013; Bizjak, Jenko-Pražnikar \& Seljak, 2014; Streppel et al., 2013). The observed correlation coefficients $(r)$ between SQ-FFQ and 2DRs were 0.38, $0.34,0.35$ and 0.35 , for EPA, DHA, ALA and total $\Omega-3$, respectively, in this study. These figures were slightly higher than that of the studies that performed unadjusted energy intake, such as a study comparing SQ-FFQ and three-day diet records (3DRs) among Japanese women in the late pregnancies where the correlation coefficients $(r)$ were 0.37, $0.34,0.32$ and 0.32 for EPA, DHA, ALA and total $\Omega-3$, respectively (Kobayashi et al., 2017), and another study that compared 2DRs and SQ-FFQ among pregnant women in Malaysia $(r=0.24$ for fat) (Loy et al., 2011). However, in another study where energy-adjustment was done, the correlation coefficients were $r=0.39$ for total $\Omega-3$ and $r=0.42$ for LC-PUFA (Bizjak et al., 2014) were higher than the coefficient found in the present study. As the correlations in this study are comparable with those reported among other groups of pregnant women, the $\Omega-3$ SQ-FFQ that has been developed may be considered valid for use in further studies.

The cross-classification of quintiles is different from correlation as the former is more informative when reporting the capacity of an assessment method to rank persons in relation to their intakes (Zhang et al., 2015). One study reported that FFQ can be an effective instrument if the result of cross-classification could categorise $>70 \%$ of respondents into the same or adjacent quintile (Barbieri et al., 2013). The present study has fulfilled this criterion. Interestingly, the result of the correlation test in this study is similar to that of the cross-classification test in that it could rank fat and all fatty acids $>80 \%$ into correctly and adjacent quintile, indicating good validity for the methods. This finding is similar with the results of study of 41 pregnant women that found higher agreement based on cross validation (quartiles) from 3DRs and FFQ for ALA, total $\Omega-3$, and LA (Zhang et al., 2015). Although agreement was found only for the total

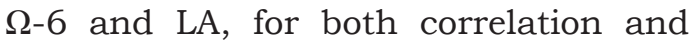
cross-classification tests, it suggested good validity for the newly developed SQFFQ for total fat and fatty acids.

Some validation studies have used blood biomarkers for dietary evaluation. However, the use of biomarkers may be challenging because of its reliability and sensitivity for pregnant women who tend to have different food patterns (Sartorelli et al., 2012; Zhang et al., 2015) and an increment of maternal plasma volume (Parker et al., 2015). Therefore, dietary assessment methods (e.g. food recall, SQFFQ) may be more reliable since it can reflect the changing of dietary patterns during pregnancy and thus can be used for dietary evaluation. Nevertheless, caution should be exercised when using dietary evaluation since it is based on selected methods and the use of food composition tables as well as calculation when the nutrients of interested are not available. The use of food recall as a reference may be subjective and prone to error because it relies on memory (Gibson, 2005). Another study reported that food recall reflected the different kinds of memory and was suitable for use in specific populations and among individuals of low literacy level and motivation (Brunst et al., 2016; Gibson, 2005). Compared to the FFQ which related to generic memory, the food recall relies on episodic memory (Vioque et al., 2016). In the current study, we 
used 2DRs, not a minimal of 3DRs as used by many studies, to compare the women's intake with SQ-FFQ for a validation study. Arguably, it may be inadequate to capture the habitual intake of pregnant women. However, Loy et al. (2011) used 2DRs as a comparison and found the SQ-FFQ to be a valid tool to collect and rank individual dietary intake for prospective study. In the current study, the unavailability of existing Indonesian FCTs for $\Omega-3$ fatty acids food source may hinder the accuracy of calculation of Indonesian food and may under- or over-estimate the intake. To control this possible bias, we selected the closest or similar foods in the FCT of other countries to estimate fatty acid content in Indonesian foods. As a result, the same reference food item was used for several different foods (e.g. fish group) although the research team had tried to find the closest genus by fish classification (Schakel et al., 1997). In addition, to have representative results, this validation study included randomly selected subjects with similar characteristics with respect to age, social-economic, education level, pregnancy history, smoking exposure and nutritional status in The Project of Role of Nutrition, Maternal Factors, and Health Service in Microbiota Composition and Birth Weight in Jakarta.

The newly developed SQ-FFQ can be used to estimate the intakes of $\Omega-3$ LC-PUFA intakes among pregnant women in large urban settings. Since reported intakes of $\Omega$-3 LC-PUFA are only available from Bangladesh and India (Koletzko et al., 2014), this study provides new information intake in another developing countries, by using a simple, easy and valid tool. Nutritional education of pregnant women can also be improved with the new information on $\Omega$-3 LC-PUFA that this study has generated to help them identify and choose main sources of this important nutrient.

\section{CONCLUSION}

The present study has shown that there is agreement between the two dietary methods, SQ-FFQ and 24-h recall, based on Bland Altman approach. The newly developed SQ-FFQ is reasonably valid for assessing the DHA, EPA and AA intake among pregnant women. Absolute validation and reproducibility studies of pregnant women in each trimester using biomarkers are recommended.

\section{Acknowledgement}

This study and its publication has been supported by the United States Agency for International Development (USAID) through the Sustainable Higher Education Research Alliance (SHERA) program for Universitas Indonesia's Scientific Modelling, Application, Training for City Centered Innovation and Technology (SMART CITY) Project, Grant \#AID-497-A-1600004, Sub-Grant \#IIE00000078-UI-1.

\section{Authors' contributions}

DA, designed this present study, conducted data collection, analysed and interpreted data, prepared the draft manuscript; RA, coordinated the design of the overall umbrella study entitled 'Role of Nutrition, Maternal Factors, and Health Service in Microbiota Composition and Birth Weight in Jakarta', designed this present study, conducted data collection, analysed and interpreted data, contributed to developing the study design, writing the manuscript, coordinated and decided on the final draft of manuscript for submission; HK and EP, contributed to the development of the study design and manuscript preparation; all the authors have read the whole manuscript and have approved its publication.

\section{Conflict of interest}

The authors declare they have no competing interests.

\section{References}

Ambrosini GL, O'Sullivan TA, De Klerk NH, Mori TA, Beilin LJ \& Oddy WH (2011). Relative validity of adolescent dietary patterns: a comparison of a FFQ and $3 \mathrm{~d}$ food record. $\mathrm{Br} J$ Nutr 105(04):625-633. doi: 10.1017/ S0007114510004137. 
Angkasa D, Tambunan V, Khusun H, Witjaksono F \& Agustina R (2017). Inadequate dietary alpha-linolenic acid intake among Indonesian pregnant women is associated with lower newborn weights in urban Jakarta. Asia Pac J Clin Nutr 26(Supplement):S9. doi: 10.6133/ apjen.062017.s1.

Ansari MR, Agustina R, Khusun H, Prafiantini E, Cahyaningrum $F$ \& Permadhi I (2016). Development and evaluation of a semiquantitative food frequency questionnaire for estimating omega- 3 and omega- 6 fatty acid intakes in Indonesian children. Asia Pac $J$ Clin Nutr 25(S1):s20-s29. doi: 10.6133/ apjen.122016.s4.

Barbieri P, Nishimura RY, Crivellenti LC \& Sartorelli DS (2013). Relative validation of a quantitative FFQ for use in Brazilian pregnant women. Publ Hlth Nutr 16(08):1419-1426. doi: $10.1017 / \mathrm{S} 1368980012003783$.

Berger J, Blanchard G, Ponce MC, Chamnan C, Chea M, Dijkhuizen M, Doak C, Doets Esmee, Fahmida U, Ferguson E, Hulshof P, Kameli Y, Kuong K, Akkhavong K, Sengchanh K, Le Mai B, Lua Tran T, Muslimatun S, Roos N, Shophonneary P, Wieringa F, Wasantwisut E \& Winichagoon P (2013). The SMILING Project: a North-South-South collaborative action to prevent micronutrient deficiencies in women and young children in Southeast Asia. Food Nutr Bull 34(2Suppl1):S133-S139. doi: $10.1177 / 15648265130342$ S1 15.

Bizjak M, Jenko-Pražnikar Z \& Seljak BK (2014). Development and validation of an electronic FFQ to assess food intake in the Slovene population. Publ Hlth Nutr 17(08):1729-1737. doi: $10.1017 / \mathrm{S} 1368980013002577$.

Bland JM \& Altman DG (1999). Measuring agreement in method comparison studies. Stat Methods Med Res 8(2):135-160.

Brunst KJ, Kannan S, Ni YM, Gennings C, Ganguri HB \& Wright RJ (2016). Validation of a food frequency questionnaire for estimating micronutrient intakes in an urban US sample of multi-ethnic pregnant women. Matern Child Hlth $J$ 20(2):250-260. doi: 10.1007/s10995015-1824-9.

Central Bureau of Statistic (2014). Statistical Yearbook of Indonesia 2014: Statistic Indonesia. From https://www.bps.go.id/ statictable/2014/09/08/950/rata-ratakonsumsi-per-kapita-seminggu-beberapamacam-bahan-makanan-penting-2007-2017. html. [Retrieved October 242014 ].
Colón-Ramos U, Racette SB, Ganiban J, Nguyen TG, Kocak M, Carroll KN, Volgyi E \& Tylavsky FA (2015). Association between dietary patterns during pregnancy and birth size measures in a diverse population in Southern US. Nutrients 7(2):1318-1332. doi: 10.3390/nu7021318.

Erhardt J (2014). Nutrisurvey software version 2007. [Updated 2012/04/04; cited 2007/08/08]. From http://www.nutrisurvey. de/. [Retrieved July 18 2015].

FAO (2016). The State of World Fisheries and Aquaculture. Food and Agricultural Organization. From http://www.fao.org/3/ai5555e.pdf. [Retrieved September 12 2017].

Freeman MP, Hibbeln JR, Wisner KL, Davis JM, Mischoulon D, Peet M, Keck PEJ, Marangell LB, Richardson AJ, Lake J \& Stoll AL (2006). Omega-3 fatty acids: evidence basis for treatment and future research in psychiatry. $J$ Clin Psychi 67(12): 1954.

Gibson RS (2005). Principles of nutritional assessment. Oxford University Press, New York.

Goldberg G, Black A, Jebb S, Cole T, Murgatroyd P, Coward W \& Prentice A (1991). Critical evaluation of energy intake data using fundamental principles of energy physiology: 1. Derivation of cut-off limits to identify underrecording. Eur J Clin Nutr 45(12):569-581.

Kobayashi M, Jwa SC, Ogawa K, Morisaki N \& Fujiwara T (2017). Validity of a food frequency questionnaire to estimate longchain polyunsaturated fatty acid intake among Japanese women in early and late pregnancy. J Epid 27(1):30-35. doi: 10.1016/j. je.2016.07.001.

Koletzko B, Boey CC, Campoy C, Carlson SE, Chang N, Guillermo-Tuazon MA, Joshi S, Prell C, Quack SH, Sjarif DR, Su Y, Supapannachart S, Yamashiro Y \& Osendarp SJ (2014). Current information and Asian perspectives on long-chain polyunsaturated fatty acids in pregnancy, lactation, and infancy: systematic review and practice recommendations from an early nutrition academy workshop. Ann Nutr Metab 65(1):49-80. doi: 10.1159/000365767.

Loy SL, Marhazlina M, Azwany Y \& Jan JM (2011). Development, validity and reproducibility of a food frequency questionnaire in pregnancy for the Universiti Sains Malaysia birth cohort study. Mal J Nutr 17(1):1-18. 
Madanijah S, Briawan D, Rimbawan R, Zulaikhah $Z$, Andarwulan N, Nuraida L, Sundjaya $T$, Murti L, Shah P \& Bindels J (2016). Nutritional status of pre-pregnant and pregnant women residing in Bogor district, Indonesia: a crosssectional dietary and nutrient intake study. $\mathrm{Br} J$ Nutr 116(S1):S57-S66. doi: 10.1017/ S000711451600057X.

Muthayya S, Dwarkanath P, Thomas T, Ramprakash S, Mehra R, Mhaskar A, Mhaskar $\mathrm{R}$, Thomas A, Bhat S, Vaz M \& Kurpad AV (2009). The effect of fish and $\omega-3$ LCPUFA intake on low birth weight in Indian pregnant women. Eur J Clin Nutr 63(3):340-346. doi:10.1038/ sj.ejcn.1602933.

National Institute of Health Research and Development (2013). Riset kesehatan dasar. Kementerian Kesehatan Republik Indonesia. From http://www.depkes.go.id/resources/ download/general/Hasil\%20Riskesdas $\% 20$ 2013.pdf. [December 20 2015].

National Institute of Health Research and Development (2014). Studi Diet Total, Survei Konsumsi Makanan Individu Indonesia 2014. Badan Penelitian Dan Pengembangan Kesehatan. Jakarta: Kementerian Kesehatan Republik Indonesia. From http://labdata. litbang.depkes.go.id/riset-badan-litbangkes/ menu-riskesnas / menu-rikus / 392-rikussdt-2014. [Retrieved February 11 2016].

Parker G, McClure G, Hegarty BD \& Smith IG (2015). The validity of a food frequency questionnaire as a measure of PUFA status in pregnancy. BMC Pregnancy Childbirth 15(1):60. doi: 10.1186/s12884-015-0494-3.

Puwastien P, Burlingame B, Raroengwichit M \& Sungpuag P (2000). ASEAN food composition tables. Institute of Nutrition, Mahidol University (INMU), ASEANFOODS Coordinator and INFOODS Regional Database Centre, Bangkok, Thailand. From http://www.inmu. mahidol.ac.th/aseanfoods/composition_data. html. [Retrieved May 5 2015].
Sartorelli D, Nishimura R, Castro G, Barbieri P \& Jordao A (2012). Validation of a FFQ for estimating $\omega-3, \omega-6$ and trans fatty acid intake during pregnancy using mature breast milk and food recalls. Eur J Clin Nutr 66(11):12591264. doi: $10.1038 /$ ejcn.2012.127.

Schakel SF, Buzzard IM \& Gebhardt SE (1997). Procedures for estimating nutrient values for food composition databases. J Food Compos Anal 10(2):102-114.

Schofield W (1984). Predicting basal metabolic rate, new standards and review of previous work. Hum Nutr Clin Nutr 39:5-41.

Streppel MT, de Vries JH, Meijboom S, Beekman M, de Craen AJ, Slagboom PE \& Feskens EJ (2013). Relative validity of the food frequency questionnaire used to assess dietary intake in the Leiden Longevity Study. Nutr J 12(1):75. doi: 10.1186/1475-2891-12-75.

Vioque J, Gimenez-Monzo D, Navarrete-Muñoz EM, Garcia-de-la-Hera M, Gonzalez-Palacios S, Rebagliato M, Ballester F, Murcia M, Iñiguez C \& Granado F (2016). Reproducibility and Validity of a Food Frequency Questionnaire Designed to Assess Diet in Children Aged 4-5 Years. PLoS One 11(11):e0167338. doi: 10.1371/journal.pone.0167338.

Willett W (2012). Nutritional epidemiology. Oxford University Press. New York.

Zhang H, Qiu X, Zhong C, Zhang K, Xiao M, Yi N, Xiong G, Wang J, Yao J, Hao L, Wei S, Yang N \& Yang X (2015). Reproducibility and relative validity of a semi-quantitative food frequency questionnaire for Chinese pregnant women. Nutr J 14(1):56. doi: 10.1186/s12937-0150044-x. 